\title{
Editorial
}

\section{On succeeding to success}

The scientific discovery I treasure most was one I reported in a paper (Antimicrob. Agents Chemother. 27 974-976, 1985) that in the 25 years since its publication failed to receive a single citation, excepting self-citations. [Forever practical, my friend Hans VanEtten presented me a T-shirt with the first page printed on it. The paper being barely three pages long, the T-shirt very nicely conveyed its gist. But donning it only made the paper more widely unread.] So the warning, in the November 2009 Springer "Authorzone" eNewsletter, that the impact factor, the average number of citations received by journals for articles published in the previous two years is "the most important quality assessment tool in scientific journal publishing" was uncannily well timed. Only a few days previously I had formally accepted the responsibility of assuming the Editorship of the Journal of Biosciences in the New Year. The message? While scientists may declare indulgent pride and satisfaction for their un-cited papers, such boastfulness is out of place for an editor.

"What is truth?" jested Pontius Pilate but did not wait for an answer, presumably surmising that "truth" in any case is relative. In this, my first attempt to editorialize, I beg you to indulge me a Pilatean "what is citation?" Many are perfunctory nods to acknowledge earlier findings that set the stage for the investigation at hand. To such run of the mill citations let us assign a "B" grade. And a " $\mathrm{C}$ " to citations inserted into the revised manuscript at the referee's behest. Citation in an article devoted to the one being cited, such as the "Clipboard" genre, could justify an "A+". And citations that are actually absent from the main text but inadvertently remain in the "References" because of sloppy revision deserve a "D". In short, citations are not all equal. Impact factor calculations do not distinguish gradations among citations, yet everyone stoically accepts their verdict, much as they do the verdict of elections, vox populi. But is the voice of Thomson Reuters Science Citation Index vox dei? Unfortunately, there is no better way of rating articles, short of actually reading them.

I cannot now resist sneaking in the citation I cherish most. It was received by two of my papers (Genetics 157 1581-1590, 2001 and Fungal Genet. Newslett. 48 13-14, 2001) and was made in a 2007 article authored by, among others, David Perkins, Michael Freitag, Eric Selker and Daniel Ebbole, among the foremost stalwarts of fungal genetics. An 18 line section of the "Results", the whole of "Table 5", and a paragraph in the "Discussion" describe studies that the authors fulsomely acknowledge were motivated by our earlier findings. It was the kind of citation I would want my mother to see. Adding poignancy to the citation was the fact that David Perkins passed away just a month before this paper was published, and I never got to thank him for his generosity.

I chose "citation and impact factor" as the theme of this editorial to help me express my selfconsciousness on assuming editorship of what arguably is the "flagship" science journal of South Asia. Credit for bringing the Journal to this status goes to my predecessors and their editorial teams whose stewardship made everyone associated with the Journal swell with pride, authors, referees, editors, office staff, the Indian Academy of Sciences and Springer. And yes, writing this short essay gave me the opportunity to introduce myself, cited or not.

Durgadas P KaSBEKar

Editor 